\title{
Correction to: A methodology for quantifying the impact of casting procedure on anisotropy in fiber-reinforced concrete using X-ray CT
}

\author{
Tyler Oesch $(D)$ Eric Landis - Daniel Kuchma
}

Published online: 27 March 2019

(C) RILEM 2019

Correction to: Materials and Structures (2018) 51:73 https://doi.org/10.1617/s11527-018-1198-8

The article Correction to: A methodology for quantifying the impact of casting procedure on anisotropy in fiber-reinforced concrete using X-ray CT, written by Tyler Oesch, Eric Landis, Daniel Kuchma, was originally published online without Open Access. After publication in volume 51, article ID 73 RILEM decided to grant the author to opt for open choice and to make the article an open-access publication. Therefore, the copyright of the article has been changed to (c) The Author(s) 2018 and the article is forthwith distributed under the terms of the Creative Commons Attribution 4.0 International License (http://creativecommons.org/licenses/by/4.0/), which permits use, duplication, adaptation, distribution and reproduction in any medium or format, as long as you give appropriate credit to the original author(s) and the source, provide a link to the Creative Commons license and indicate if changes were made.

Publisher's Note Springer Nature remains neutral with regard to jurisdictional claims in published maps and institutional affiliations.

The original article can be found online at https://doi.org/10.1617/s11527-018-1198-8.

T. Oesch $(\bowtie)$

Bundesanstalt für Materialforschung und -prüfung

(Federal Institute for Materials Research and Testing),

Berlin, Germany

e-mail: tyler.oesch@bam.de

E. Landis

Department of Civil and Environmental Engineering,

University of Maine, Orono, ME, USA

D. Kuchma

Department of Civil and Environmental Engineering,

Tufts University, Medford, MA, USA 